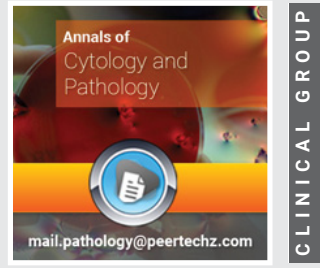

\title{
Development of A
}

\section{Management Guideline Wheel for Abnormal Pap Smears and Related Cervical Pathology}

\author{
M Samy Ismail* \\ Professor Mahmoud Samy Ismail, OBGYN Department, King Hamad University Hospital, Kingdom of \\ Bahrain, Bahrain
}

Received: 01 February, 2020

Accepted: 11 March, 2020

Published: 12 March, 2020

*Corresponding author: Mahmoud Samy Ismail, Professor, OBGYN Department, King Hamad University Hospital, Building 2435, Road 2835, Block 228 , Busaiteen P.O Box 24343, Al Muharraq, Kingdom of Bahrain, Bahrain, Tel: +97335593048;

E-mail: samyismael@hotmail.com

Keywords: Pap smear; Cervical pathology; Management of abnormal cervical pap smears

https://www.peertechz.com

Check for updates

\begin{abstract}
A Management Guideline Wheel for Abnormal Cervical Pap Smears and related Cervical Pathology has been designed and developed to facilitate a standard and improve the quality of care in management of abnormal cervical cytology, precancerous lesions and cancerous lesions of the cervix. Each step of the wheel takes into account the context of the patient's medical condition, which include past medical/surgical history, patient compliance, patient awareness regarding the screening process, and the availability of treatment modalities for precancerous cervical lesions.

Management guidelines were revised by comparing existing guidelines on cervical cancer screening from the World Health Organization (WHO), the American guidelines, guidelines of the American College of Obstetricians and Gynecologists (ACOG), the United States Preventive Services Task Force (USPSTF), the American Cancer Society (ACS), the American Society for Colposcopy and Cervical Pathology (ASCCP), the American Society for Clinical Pathology (ASCP), the American College of Physicians (ACP) and the American Society for Colposcopy and Cervical Pathology, the guidelines from Singapore and Canada, the National Institute for Healthcare and Excellence (NICE) and National Health Service (NHS) of the UK.
\end{abstract}

\section{Abbreviations}

ACOG: American College of Obstetricians and Gynecologists; USPSTF: United States Preventive Services Task Force; ACS American Cancer Society; ASCCP: American Society for Colposcopy and Cervical Pathology; ASCP: American Society for Clinical Pathology; CDC: Centers for Disease Control and Prevention; ACP: American College of Physicians; NICE: National Institute for Health and Care Excellence; NHS: National Health Service; VIA: Visual Inspection with Acetic Acid; HPV: Human Papillomavirus; ASCUS: Atypical Squamous Cells of Undetermined Significance; LSIL: Low Grade Squamous Intraepithelial Lesion; HSIL: High Grade Squamous Intraepithelial Lesion; ASC-H: Atypical Squamous Cells in which HSIL cannot be excluded; AGC: Atypical Glandular Cells; AIS: Adenocarcinoma In Situ; CIN: Cervical Intraepithelial Neoplasia; SCC: Squamous Cell Carcinoma; LLETZ: Large
Loop Excision of the Transformation Zone; CKC: Cold Knife Conization

\section{Introduction}

Globally, there exist many different guidelines for the management of abnormal cervical cytology and related cervical pathology. As a result, different countries and societies have developed differing algorithms that vary about the steps of management following abnormal cytological or pathological results. There is no universal management guideline that all countries currently follow.

\section{About this wheel}

This Wheel integrates data collected from several international guidelines concerning the management of abnormal cervical cytology (from Pap smear) and related cervical pathology. Its aim is to be a management algorithm. 


\section{The wheel presents treatment modalities in ten steps:}

1. Routine Screening Schedule, according to the program and guideline of the country or the institute.

2. Repeat Pap Smear, either A: In 3-6 months, B: yearly, C: with the use of Endo Cervical Brush or D: in addition to Endometrial Sampling.

3. HPV Testing, either A: Screening, B: Coding, or C: Identification of Oncogenicity.

4. Treatment, either of A: Infection, B: Inflammation, C: Atrophy or D: CIN.

5. Colposcopy, with A: ECC (Endo Cervical Curettage) or B: Directed Biopsy.

6. Refer, to A: Gynaecologist or B: Oncologist.

7. Directed Therapy, by A: Ablation, B: Excision, C: Conization (using LEETZ, LEEP or Cold Knife).

8. Total Hysterectomy.

9. Guidelines, for A: CIN and B: Cervical Cancer.

10. No Further Pap Smear.

\section{How to use this wheel?}

The wheel matches up the treatment modalities/ steps/decisions, shown on the inner disk, with specific abnormal cervical cytological/histopathological conditions or characteristics shown around the outer rim. The numbers shown in the viewing slot tell the gynaecologist (user) the suggested the sequential order of steps to manage for instance a patient with a known abnormal cervical cytological/ histopathological condition or characteristic has to start and to go through (1 followed by 2-3-4-5-6-7-8-9-10). This order of steps was built following the proposed own guideline. Use of the treatment steps in the wheel is only a suggestion and the decision to follow it or another depends on the availability of other programs, resources and local guidelines. The suggested guideline is tailored and based on different internationally approved guidelines. The author welcomes any suggestions, opinions or ideas regarding the design and/or presentation of the wheel.

The specific abnormal cervical cytological/ histopathological conditions shown around the outer rim are

1. Pap Smear with Negative Malignant cells.
2. Unsatisfactory Pap Smear.

3. Abnormal Pap Smear with Abnormal Squamous Cells.

4. Abnormal Pap Smear with Low Grade Squamous Intraepithelial Lesion (LGSIL).

5. Abnormal Pap Smear with High Grade Squamous Intraepithelial Lesion (HGSIL).

6. Abnormal Pap Smear with Atypical Endo-Cervical Cells.

7. Pap Smear Post Hysterectomy.

8. CIN1.

9. $\mathrm{CIN} 2 / 3$.

10. Suspicious of Micro invasive Carcinoma.

11. Adeno Carcinoma in Situ (AIS)

12. Pap Smear Post Conization.

13. Abnormal Pap Smear in Pregnancy

(T) $2^{\text {nd }}$ and $3^{\text {rd }}$ Trimester of Pregnancy
AGC = Atypical glanadular cells
$@$ End of puerperium
\# Squamous Carcinoma
*** HPV $16-18+v e$
\$ HPV $16-18$-ve
@ Reconization
\& For 5 years
** HPV +ve
* HPV -ve

Low Grade Sq. Intraepithelial Lesion = LGSIL

High Grade Sq. Intraepithelial Lesion = HGSIL Atypical Sq. cells of Undetermind Significance $=$ ASCUS

Atypical Sq. cells High grade canot be exclude $=$ ASC-H

Cervical Intraepithelial Neoplasia $=\mathrm{CIN}$

Cervical Intraepithelial Neoplasia grade $1=$ CIN1

Cervical Intraepithelial Neoplasia grade $2=$ CIN2

Cervical Intraepithelial Neoplasia grade $3=$ CIN3

Atypical Sq. Cells = ASC 


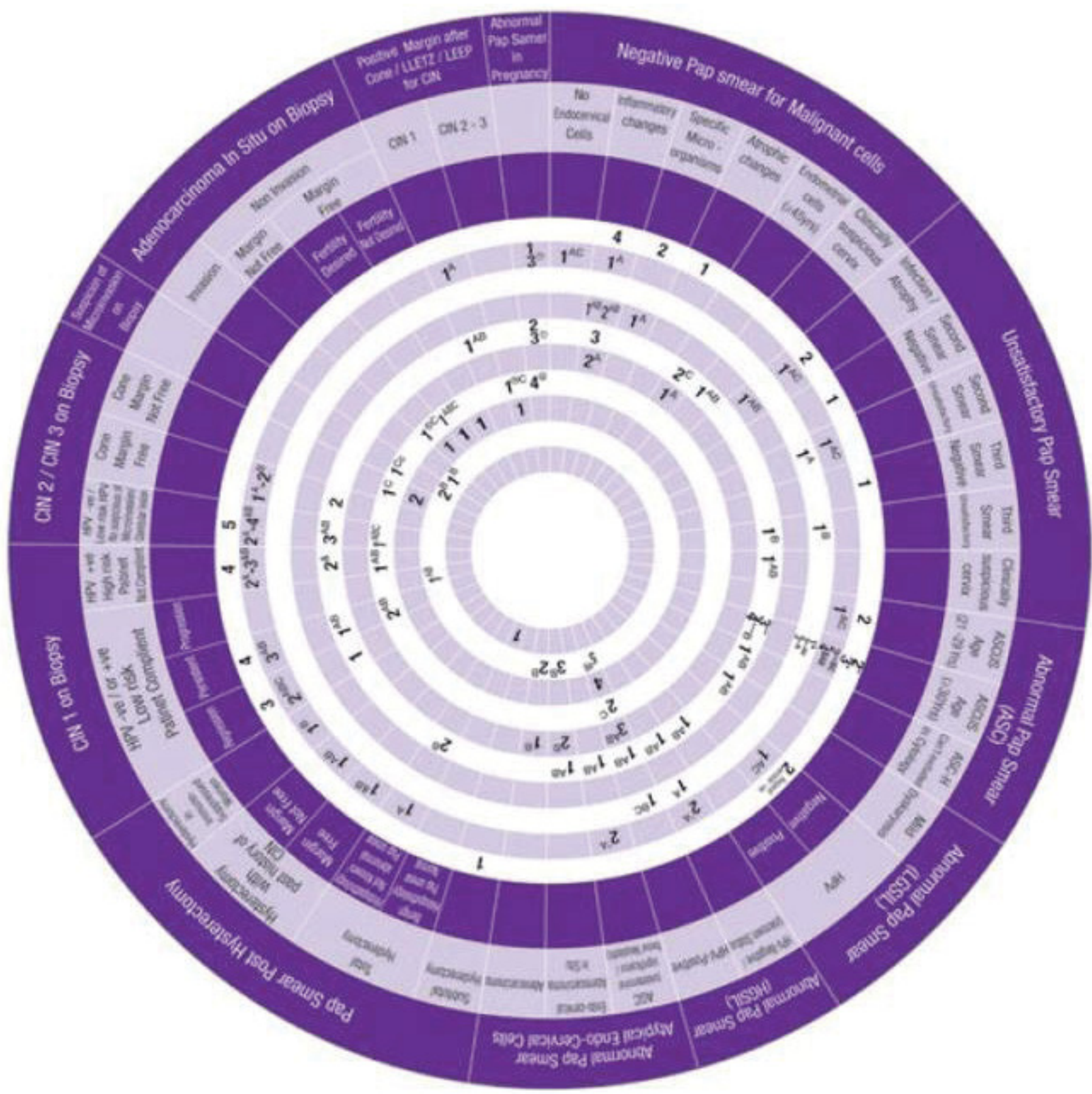

\section{Outer Wheel of Pap smear}



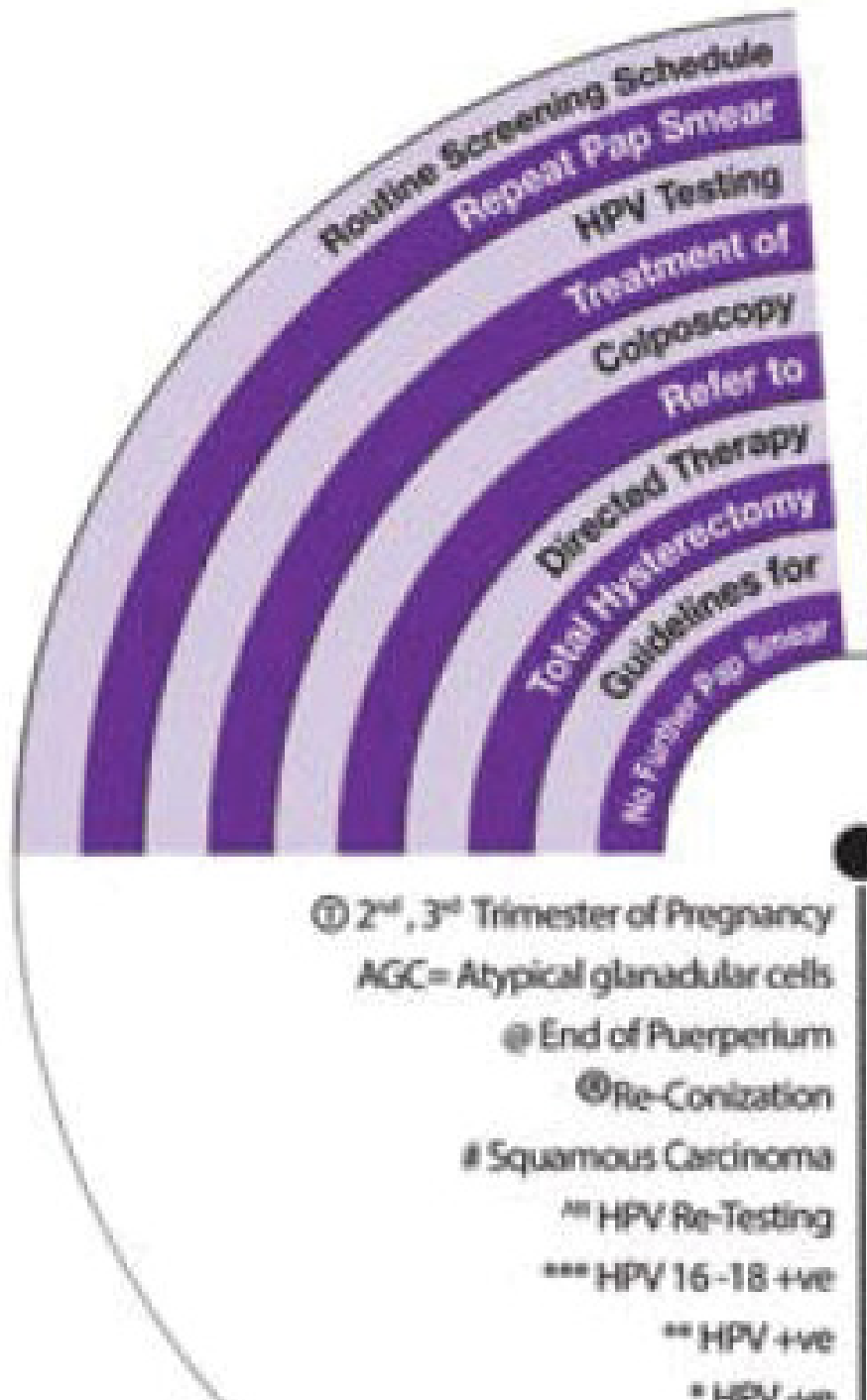
e End of Auerperium Qpe-conization 1 Squamous Carcinoma MPV Fe-Testing ** HPV $16-18$ twe *HPV +ve

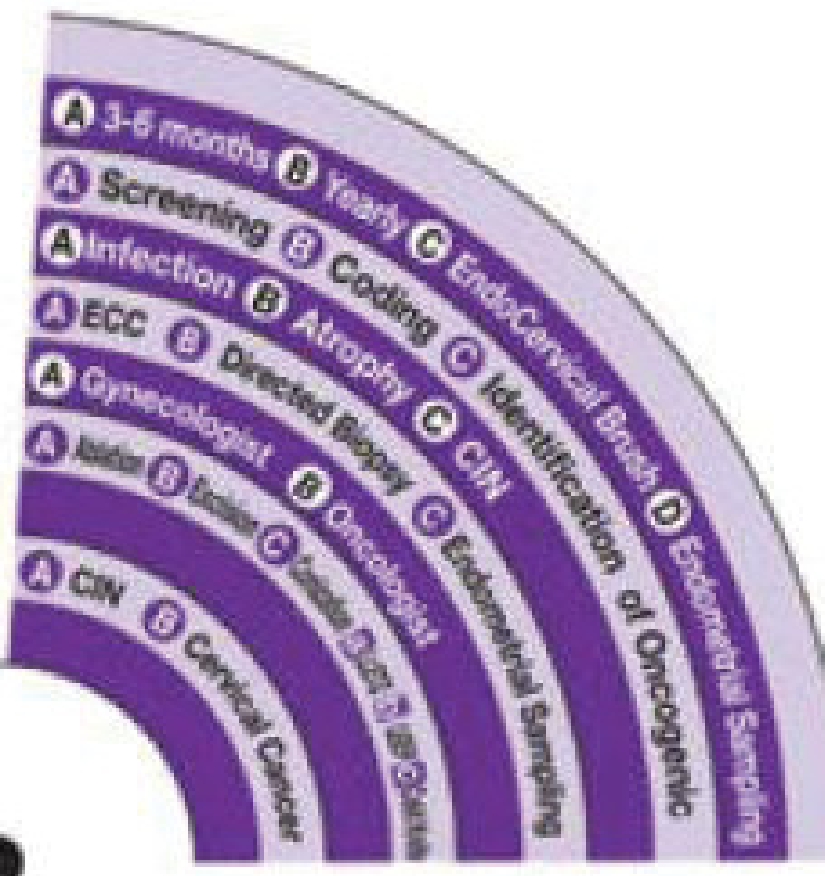

Low Grade Sq Intraepithelial Lesion = LGSIL. High Grade Sq. Intraepithelial Lesion = HGSIL Atypical Sq cells of Undetermind Sign, $=$ ASCUS

"HPV twe

"HoV 16-18-1e

*For 5 years Atypical Sq cels High grade cant exdude = ASCH Cervical Intraepithelial Neopladia $=$ CN Cervical intracpithelid Neoplania grade I = CN1 Cenkal morepthelid Neoplasiagnde $2=\mathrm{CNQ}$ Cenvical intosepithelis Neoplase grade $3=$ CN3 Atypical Sq Cells $=$ ASC

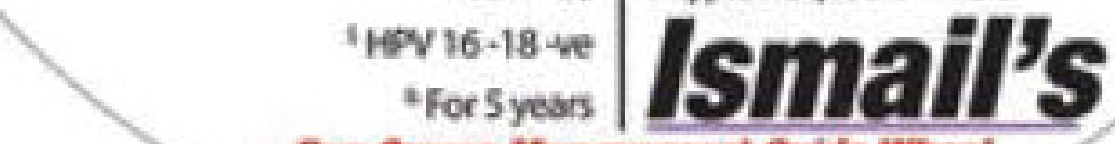

Pap Sinear Managentent Guide Wheel sampiemaeiahotrolicon

\section{Inner Wheel of Pap smear}




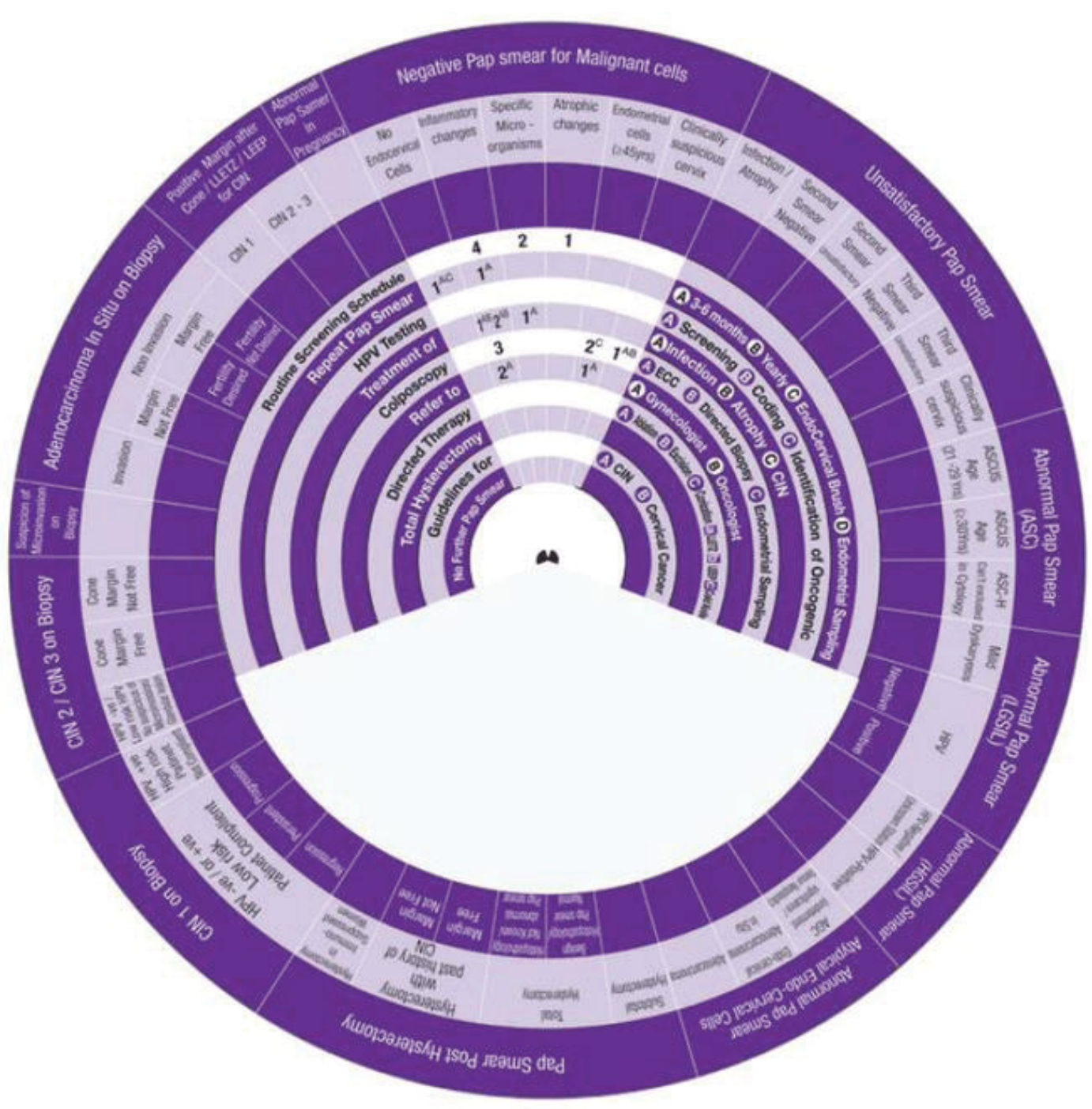

Sector 1: Management of Pap Smear with Negative Malignant cells.

Sector 1: Management of Pap Smear with Negative Malignant cells.

1. With No Endo Cervical cells, the wheel determines the management in One step:

Step $1 \rightarrow 1 \mathrm{AC} \rightarrow$ Repeat Smear+in 3-6 months + use EndoCervical Brush.

2. Presence of Inflammatory cells, the wheel determines the management in Four Steps:

Step $1 \rightarrow(1 \mathrm{AB}-1 \mathrm{~A}) \rightarrow 1 \mathrm{AB}$ Treat infection and atrophy $+1 \mathrm{~A}$ Repeat Smear in 3-6 months.

Step $2 \rightarrow(2 \mathrm{AB}-2 \mathrm{~A}) \rightarrow 2 \mathrm{AB}$ Treat infection and atrophy (If persistent) $+2 A$ Refer to Gynaecologist (if persistent finding).

Step $3 \rightarrow(3) \rightarrow$ Do Colposcopy (if persistent finding).

Step $4 \rightarrow(4) \rightarrow$ Routine Screening Schedule (If the smear becomes normal).
3. Presence of Specific micro-organism, the wheel determines the management in Two Steps:

Step $1 \rightarrow(1 \mathrm{~A}) \rightarrow 1 \mathrm{~A}$ Treat infection (with the specific antimicrobial agents).

Step $2 \rightarrow(2) \rightarrow 2$ Routine Screening Schedule.

4. Presence of Endometrial cells, the wheel determines the management in Two Steps:

Step $1 \rightarrow(1 \mathrm{~A}) \rightarrow 1 \mathrm{~A}$ Refer to Gynaecologist.

Step $2 \rightarrow(2 \mathrm{C}) \rightarrow 2 \mathrm{C}$ Do Colposcopy+Endometrial Sampling.

5. Clinically Suspicious Cervix, the wheel determines the management in One step:

Step $1 \rightarrow(1 \mathrm{AB}) \rightarrow 1 \mathrm{AB}$ Do Colposcopy+Endo-Cervical Currette (ECC)+Directed Biopsy. 


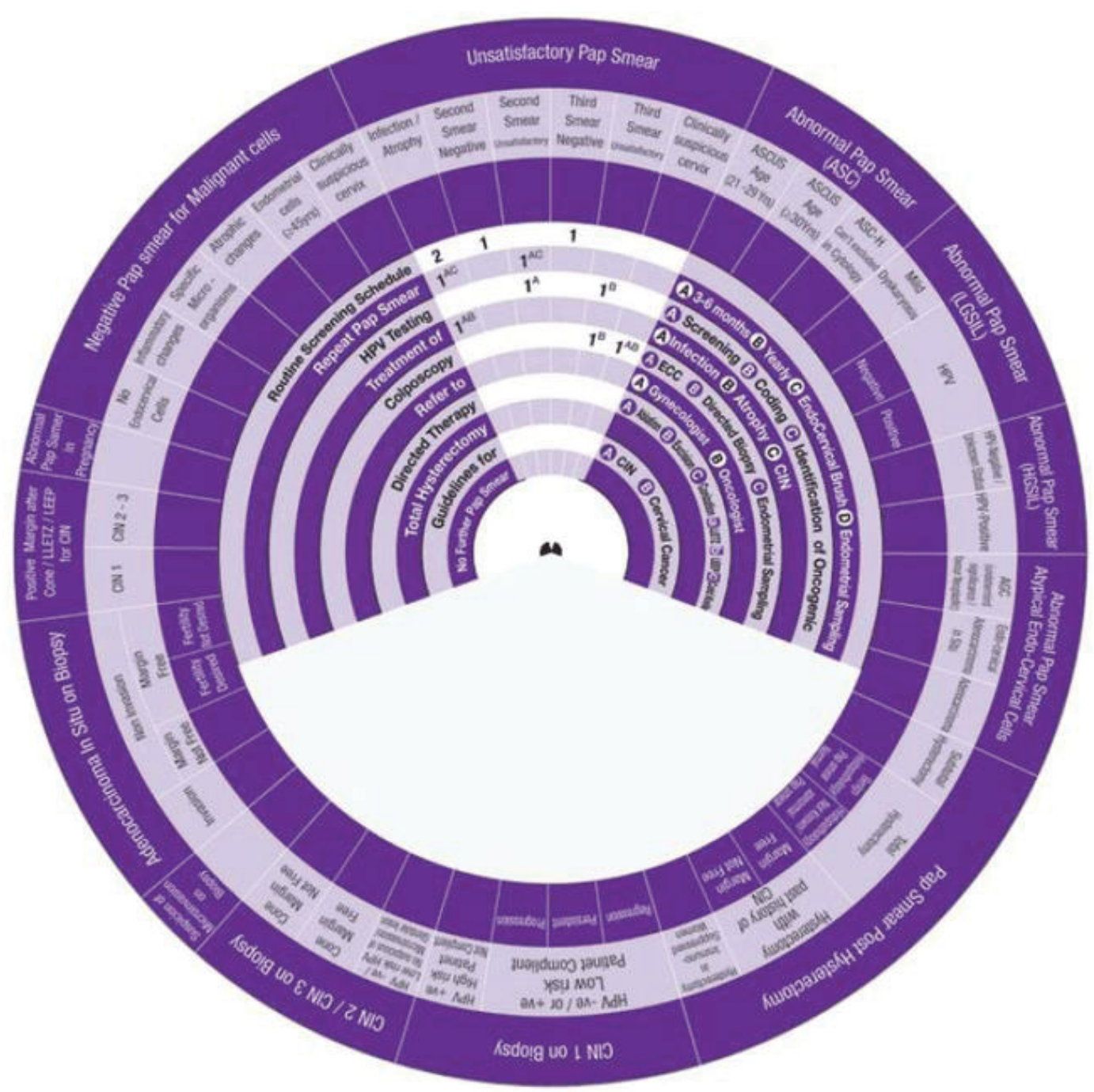

Sector 2: Management of Unsatisfactory Pap Smear

Sector 2: Management of Unsatisfactory Pap Smear.

1. Presence of Infection or Atrophy, the wheel determines the management in Two steps:

Step $1 \rightarrow(1 \mathrm{AB}-1 \mathrm{AC}) \rightarrow 1 \mathrm{AB}$ Treat infection and atrophy +1AC Repeat Smear +in 3-6 months+use Endo-Cervical Brush.

Step $2 \rightarrow(2) \rightarrow 2$ Routine Screening Schedule.

2. Second Smear becomes Satisfactory and Negative, the wheel determines the management in One Step:

Step $1 \rightarrow(1 \mathrm{AC}-1 \mathrm{~A}) \rightarrow 1 \mathrm{AC}$ Repeat Smear +in 3-6 months +use Endo-Cervical Brush +1A HPV testing Screening.

3. Second Smear becomes Unsatisfactory, the wheel determines the management in Two Steps:

Step $1 \rightarrow(1 \mathrm{~A}) \rightarrow 1 \mathrm{~A}$ Treat infection (with the specific antimicrobial agents).
Step $2 \rightarrow(2) \rightarrow 2$ Routine Screening Schedule.

4. Third Smear becomes Satisfactory and Negative, the wheel determines the management in One Step:

Step $1 \rightarrow(1 \mathrm{AC}-1 \mathrm{~A}) \rightarrow 1 \mathrm{AC}$ Repeat Smear +in 3-6 months +use Endo-Cervical Brush +1A HPV testing Screening.

5. Presence of Endometrial cells, the wheel determines the management in Two Steps:

Step $1 \rightarrow(1 \mathrm{~A}) \rightarrow 1 \mathrm{~A}$ Refer to Gynaecologist.

Step $2 \rightarrow(2 \mathrm{C}) \rightarrow 2 \mathrm{C}$ Do Colposcopy+Endometrial Sampling.

6. Clinically Suspicious Cervix, the wheel determines the management in One step:

Step $1 \rightarrow(\mathrm{AB}) \rightarrow 1 \mathrm{AB}$ Do Colposcopy+Endo-Cervical Currette (ECC)+Directed Biopsy. 


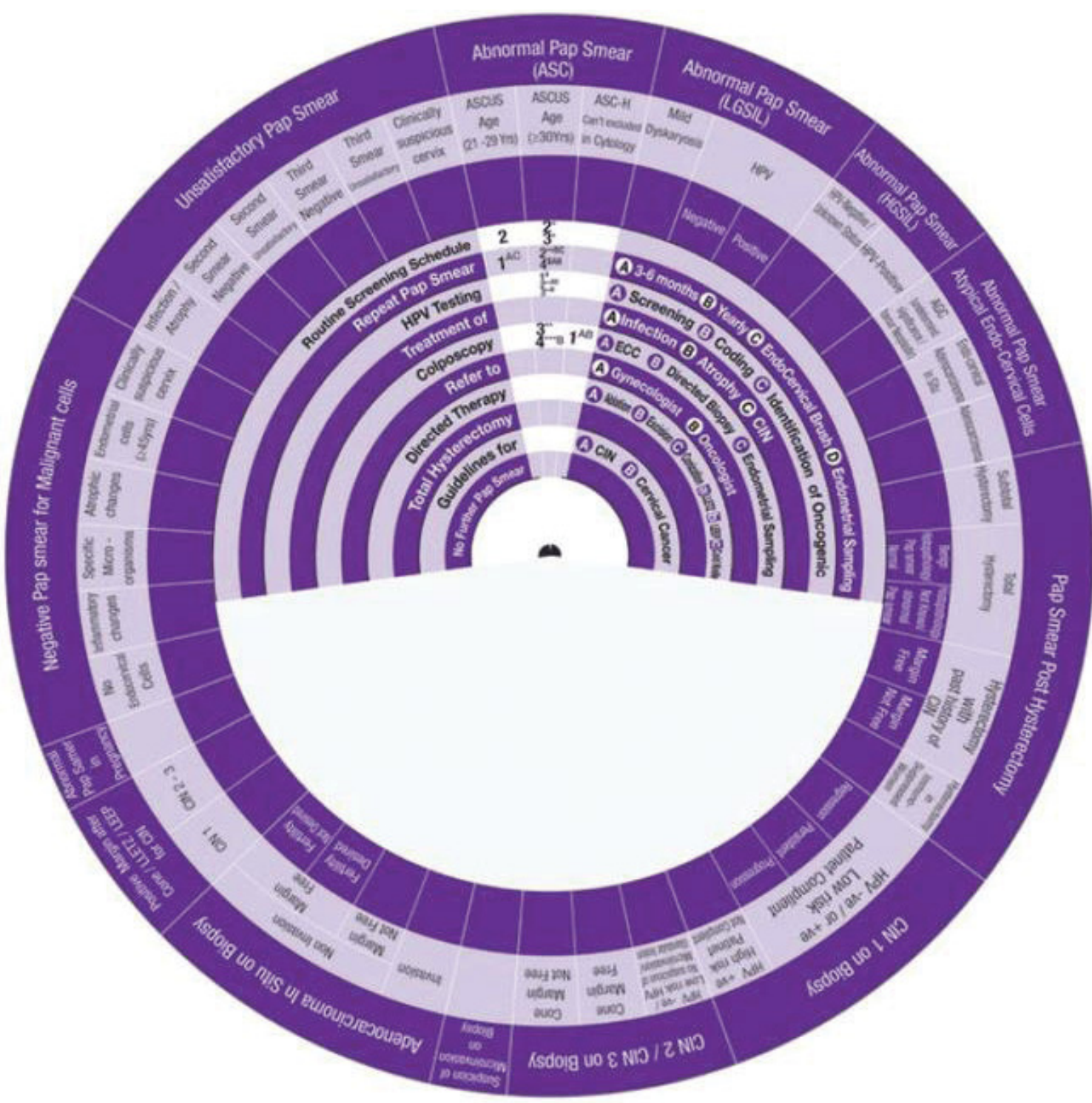

Sector 3: Management of Abnormal Pap Smear (Abnormal Squamous Cells-ASC).

Sector 3: Management of Abnormal Pap Smear (Abnormal Squamous Cells-ASC).

1. ASCUS (Age between 21-29 years), the wheel determines the management in Two steps:

Step $1 \rightarrow 1 \mathrm{AC} \rightarrow 1 \mathrm{AC}$ Repeat Smear +in 3-6 months +use Endo-Cervical Brush.

Step $2 \rightarrow 2 \rightarrow 2$ Routine Screening Schedule.

2. ASCUS (Age >30 years), the wheel determines the management in Four steps:

Step $1 \rightarrow(1 \mathrm{~A}) \rightarrow 1 \mathrm{~A}$ HPV as a screening test.

Step $2 \rightarrow(2 *-2 * * \mathrm{BC}-2 * * \mathrm{Att}) \rightarrow 2 *$ Routine Screening Schedule (If HPV test $-\mathrm{ve}$ ), $\rightarrow 2 * *$ BC Repeat smear in one year+use Endo cervical Brush, 2**Att HPV re-testing.

Step $3 \rightarrow\left(3^{*}-3^{* *}-3 * * \mathrm{~B}\right) \rightarrow 3^{*}$ Routine Screening Schedule (If the smear becomes normal and HPV test is $-v e$ ) $\rightarrow 3^{* *}$ Do Colposcopy (if persistent finding ASCUS with +ve HPV test), $\rightarrow 3 * *$ B HPV testing with Coding.

Step $4 \rightarrow\left(4 \mathrm{SAB}-4^{* * *} \mathrm{~B}\right) \rightarrow 4 \mathrm{SAB}$ Repeat Smear in 3-6months if HPV $16-18-v e) \rightarrow 4 * * * \mathrm{~B}$ Colposcopy + Directed Biopsy if HPV 16-18 +ve.

3. ASC-H (can not be excluded in Cytology), the wheel determines the management in one step:

Step $1 \rightarrow(1 \mathrm{AB}) \rightarrow 1 \mathrm{AB}$ Colposcopy with ECC+Directed Biopsy.

Sector 3: Management of Abnormal Pap Smear (Abnormal Squamous Cells-ASC). 


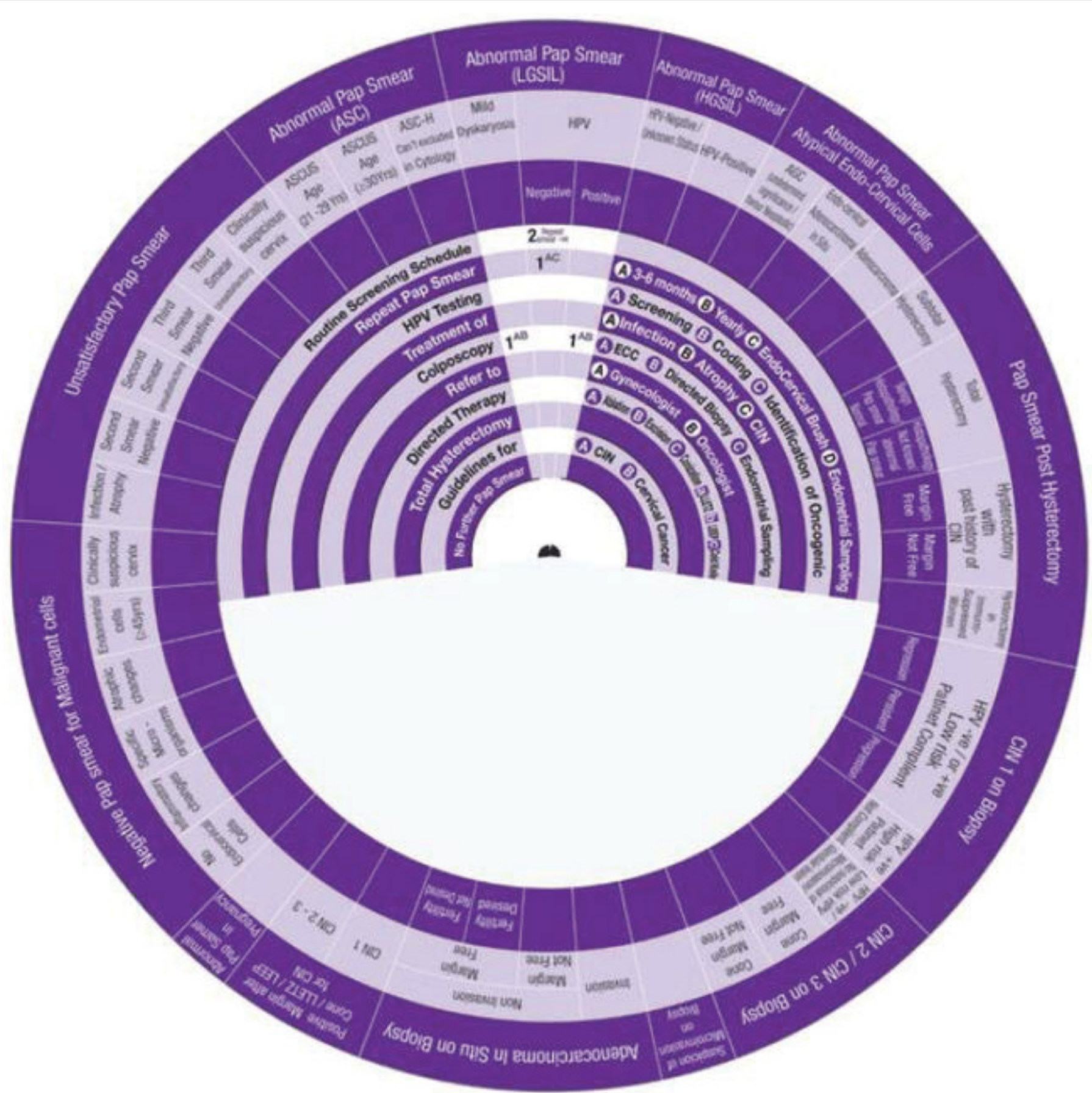

Sector 4: Management of Abnormal Pap Smear (LGSIL).

Sector 4: Management of Abnormal Pap Smear (LGSIL).

1. LGSIL (Mild Dyskaryosis), the wheel determines the management in One step:

Step $1 \rightarrow(1 \mathrm{AB}) \rightarrow 1 \mathrm{AB}$ Colposcopy with ECC + Directed Biopsy.

2. LGSIL (HPV-Negative), the wheel determines the management in Two steps:
Step $1 \rightarrow(1 \mathrm{~A}) \rightarrow 1 \mathrm{~A}$ Repeat Smear +in 3-6 months +use Endo-Cervical Brush.

Step $2 \rightarrow(2) \rightarrow 2$ Routine Screening Schedule (If Smear -ve),

3. LGSIL (HPV-Positive), the wheel determines the management in One step:

Step $1 \rightarrow(1 \mathrm{AB}) \rightarrow 1 \mathrm{AB}$ Colposcopy with ECC +Directed Biopsy. 


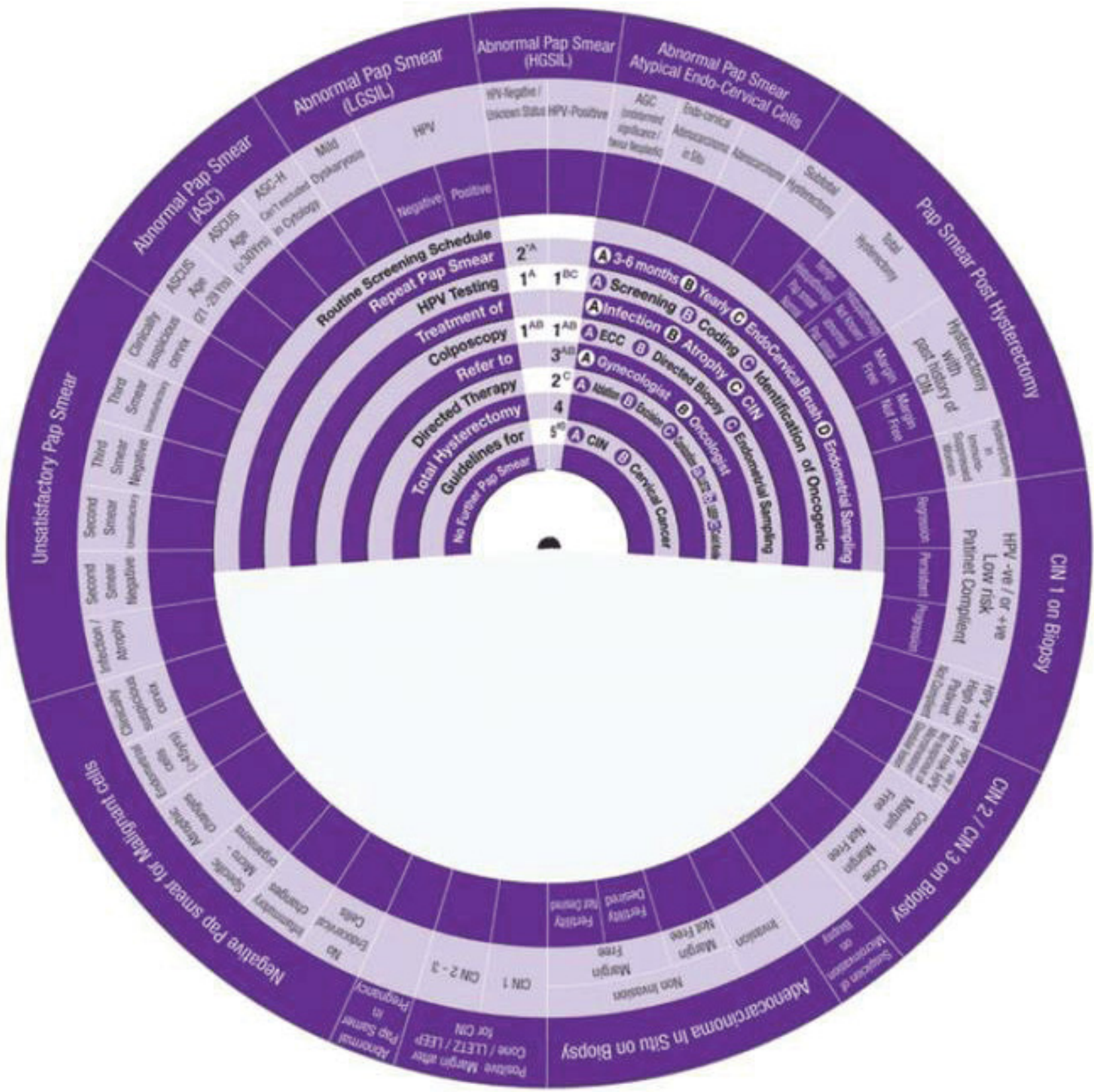

Sector 5: Management of Abnormal Pap Smear (HGSIL).

Sector 5: Management of Abnormal Pap Smear (HGSIL).

1. HGSIL (HPV -Negative or Unknown Status), the wheel determines the management in Two steps:

Step $1 \rightarrow(1 \mathrm{AB}-1 \mathrm{~A}) \rightarrow 1 \mathrm{AB}$ Colposcopy with ECC + Directed Biopsy $\rightarrow 1 \mathrm{~A}$ HPV testing Screening.

Step $2 \rightarrow(2 * A) \rightarrow 2 * A \rightarrow$ Repeat Smear HPV - ve,+in 3-6 months
2. HGSIL (HPV-Positive), the wheel determines the management in Four steps:

Step $1 \rightarrow(1 \mathrm{AB}-1 \mathrm{BC}) \rightarrow 1 \mathrm{AB}$ Colposcopy with ECC and Directed Biopsy $\rightarrow 1 \mathrm{BC}$ HPV testing Coding-Identification.

Step $2 \rightarrow(2 \mathrm{C}) \rightarrow 2 \mathrm{C}$ Directed Therapy Conization.

Step $3 \rightarrow(3 \mathrm{AB}) \rightarrow 3 \mathrm{AB}$ Refer to Gynaecologist+Oncologist.

Step $4 \rightarrow(4) \rightarrow 4$ Total Hysterectomy. 


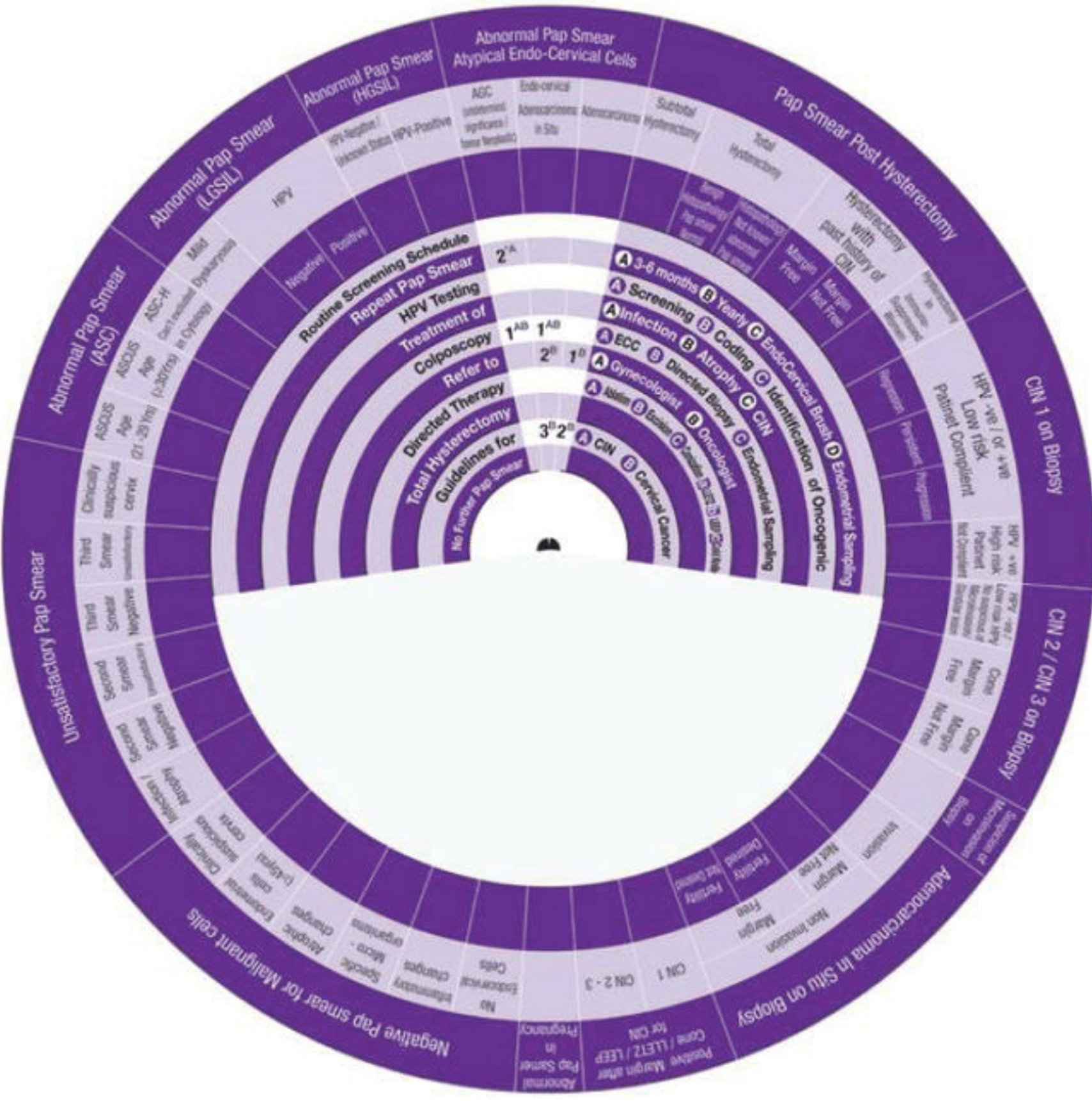

Sector 6: Management of Abnormal Pap Smear (Atypical Endo-Cervical Cells).

Sector 6: Management of Abnormal Pap Smear (Atypical Endo-Cervical Cells).

1. AGC (Undetermined Significance - Favor Neoplastic), the wheel determines the management in Two steps:

Step $1 \rightarrow(1 \mathrm{AB}) \rightarrow 1 \mathrm{AB}$ Colposcopy with ECC + Directed Biopsy.

Step $2 \rightarrow(2 * A) \rightarrow 2 * A \rightarrow$ Repeat Smear HPV - ve + in 3-6 months
2. Endo-Cervical Adenocarcinoma In-Situ, the wheel determines the management in Two steps:

Step $1 \rightarrow(1 \mathrm{AB}-1 \mathrm{BC}) \rightarrow 1 \mathrm{AB}$ Colposcopy with $\mathrm{ECC}+$ Directed Biopsy .

Step $2 \rightarrow(2 \mathrm{AB}) \rightarrow 3 \mathrm{AB}$ Refer to Gynaecologist + Oncologist.

3. Endo-Cervical Adenocarcinoma, the wheel determines the management in One step:

Step $1 \rightarrow(1 \mathrm{~B}) \rightarrow 1 \mathrm{~B}$ Refer to Oncologist. 


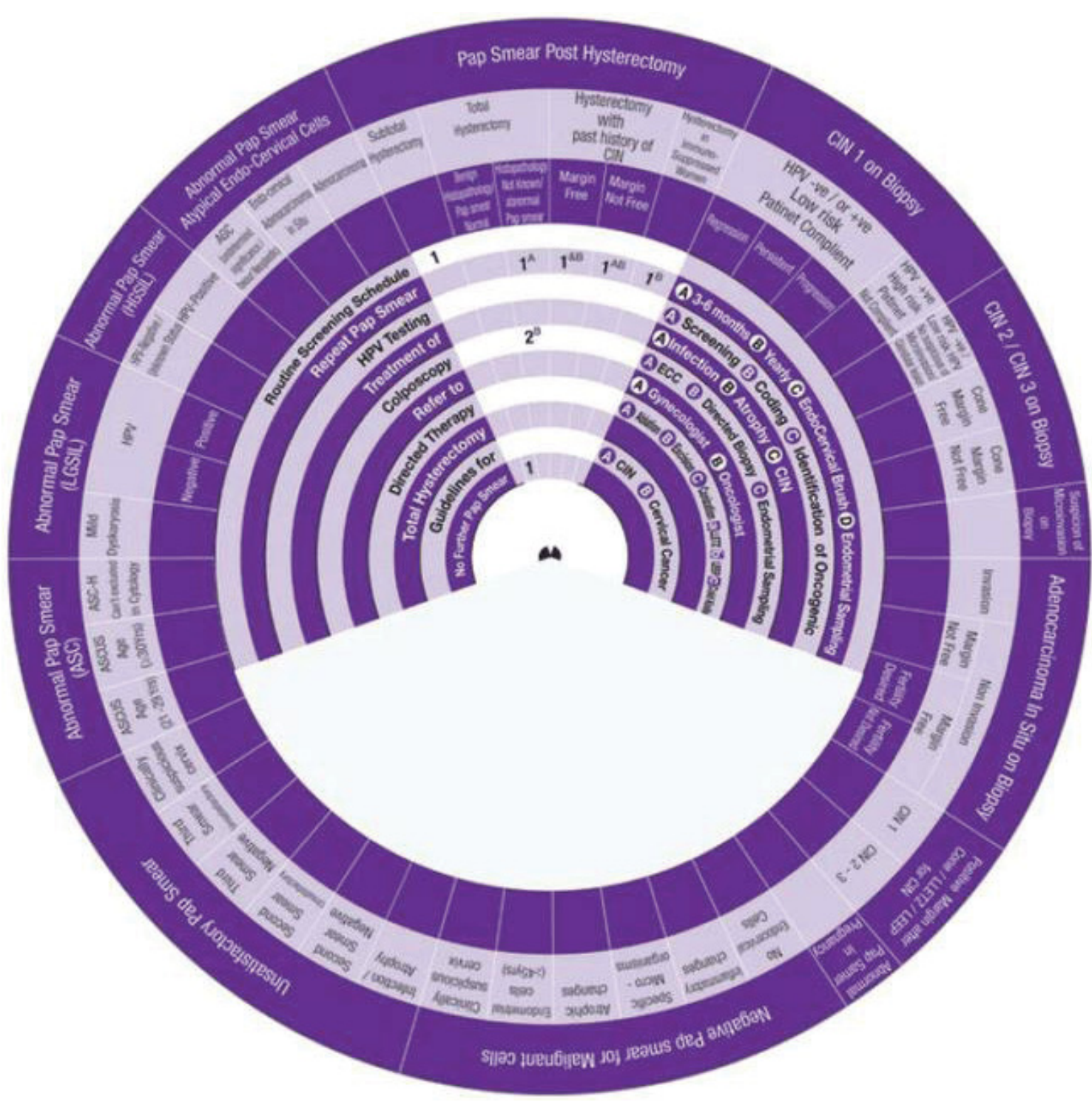

Sector 7: Management of Pap Smear Post Hysterectomy

Sector 7: Management of Pap Smear Post Hysterectomy.

1. Post Subtotal Hysterectomy, the wheel determines the management in Two steps:

Step $1 \rightarrow(1) \rightarrow$ Routine Screening Schedule.

Step $2 \rightarrow(2 * A) \rightarrow 2 * A \rightarrow$ Repeat Smear HPV-ve, + in $3-6$ months

2. Total Hysterectomy with Benign histopathology and Normal Pap Smear, the wheel determines the management in One step:

Step $1 \rightarrow(1) \rightarrow$ No Further Pap Smear .

3. Total Hysterectomy with not known histopathology or abnormal Pap Smear, the wheel determines management in Two steps:

Step $1 \rightarrow(1) \rightarrow 1$ Repeat Smear of the Vault, $\rightarrow$ If Normal No Further Smear
Step $2 \rightarrow(2 \mathrm{~A}) \rightarrow 2 \mathrm{~B}$ Colposcopy with Directed Biopsy, if Smear shows Abnormality.

4. Total Hysterectomy with past history of CIN (Margin Free), the wheel determines management in Two steps:

Step $1 \rightarrow(1 \& B) \rightarrow 1 \& B$ Repeat Smear of the Vault Yearly for five years.

Step $2 \rightarrow 2 \mathrm{~A} \rightarrow 1 \mathrm{~B}$ Colposcopy with Directed Biopsy, if Smear shows Abnormality.

5. Total Hysterectomy with past history of CIN (Margin Not Free), the wheel determines management in One step:

Step $1 \rightarrow(1 \mathrm{AB}) \rightarrow 1 \mathrm{AB}$ Repeat Smear of the Vault in 3-6 months +then Yearly .

6. Hysterectomy in immune suppressed women, the wheel determines management in One step:Step $1 \rightarrow(1 \mathrm{~B}) \rightarrow 1 \mathrm{~B}$ Repeat Smear of the Vault Yearly 


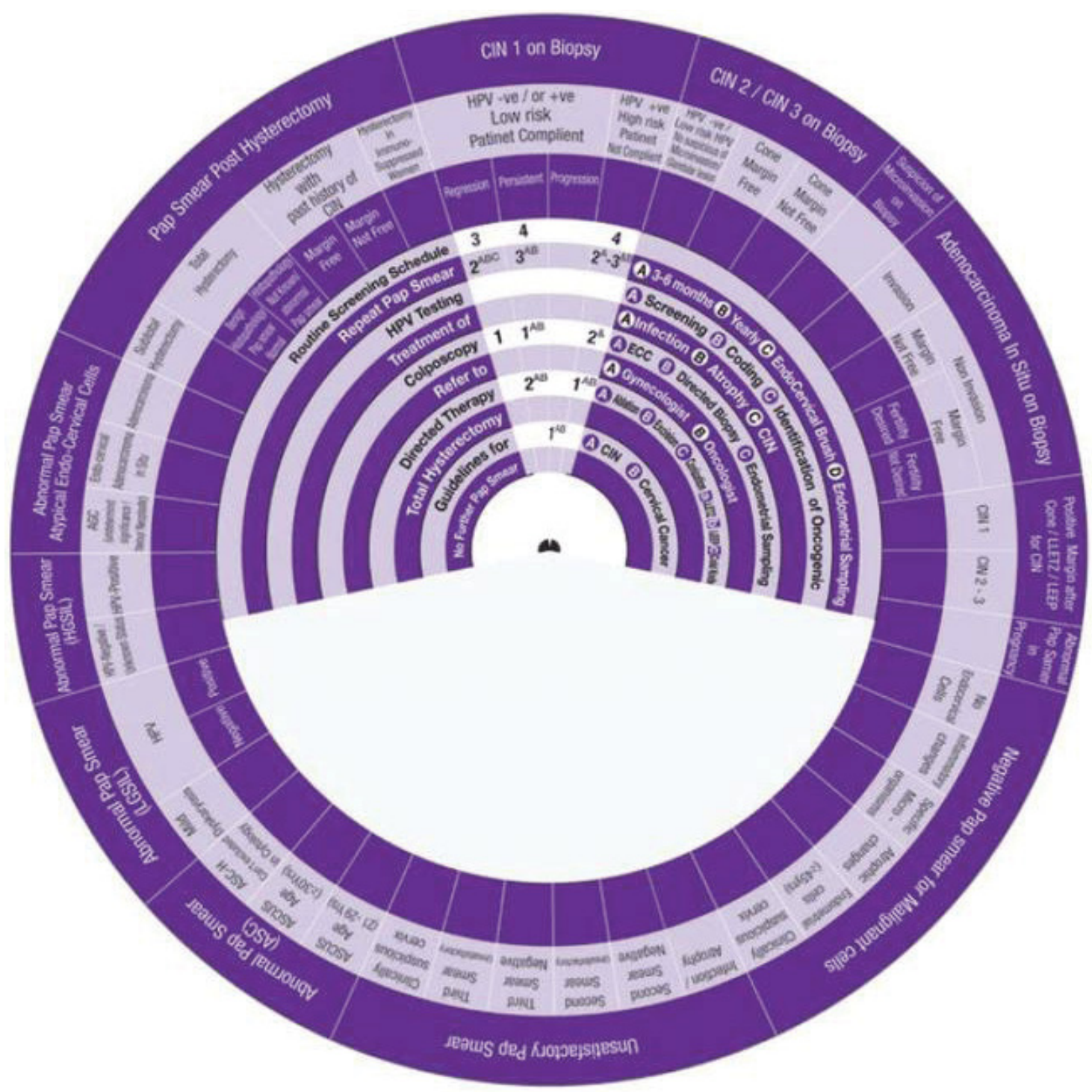

Sector 8: Management of CIN1 on Biopsy.

\section{Sector 8: Management of CIN1 on Biopsy.}

1. CIN1 on Biopsy in women with HPV Negative or Positive with low risk HPV and patient is compliant (Regression), the Wheel determines the management in Three steps:

Step $1 \rightarrow(1) \rightarrow$ Colposcopy.

Step $2 \rightarrow(2 A B C) \rightarrow$ Repeat Smear in 3-6 months, Yearly + Use Endo cervical Brush.

Step $3 \rightarrow(3) \rightarrow$ Routine Screening Schedule.

2. CIN1 on Biopsy in women with HPV Negative or Positive with low risk HPV and patient is compliant (Persistent), the Wheel determines the management in Four steps:

Step $1 \rightarrow(1 \mathrm{AB}) \rightarrow$ Colposcopy ECC + Directed Biopsy.

Step $2 \rightarrow(2 \mathrm{AB}) \rightarrow$ Directed Therapy Ablation, Excision.

Step $3 \rightarrow(3 A B) \rightarrow$ Repeat Smear in 3-6 months, Yearly.
Step $4 \rightarrow(4) \rightarrow$ Routine Screening Schedule.

3. CIN1 on Biopsy in women with HPV Negative or Positive with low risk HPV and Patient is compliant (Progression), the wheel determines the management in One step:

Step $1 \rightarrow(1 \mathrm{AB}) \rightarrow 1 \mathrm{AB}$ Refer to Gynaecologist+Oncologist.

4. CIN1 on Biopsy in women with HPV Positive with High risk HPV and patient is not compliant (Persistent), the wheel determines the management in Four steps:

Step $1 \rightarrow(1 \mathrm{AB}) \rightarrow$ Directed Therapy Ablation, Excision.

Step $2 \rightarrow(2 \mathrm{~A}-2 \&) \rightarrow$ Repeat Smear in $3-6$ months+Colposcopy Yearly for five years.

Step $3 \rightarrow(3 B \&) \rightarrow$ Repeat Smear Yearly for five years.

Step $4 \rightarrow(4) \rightarrow$ Routine Screening Schedule. 


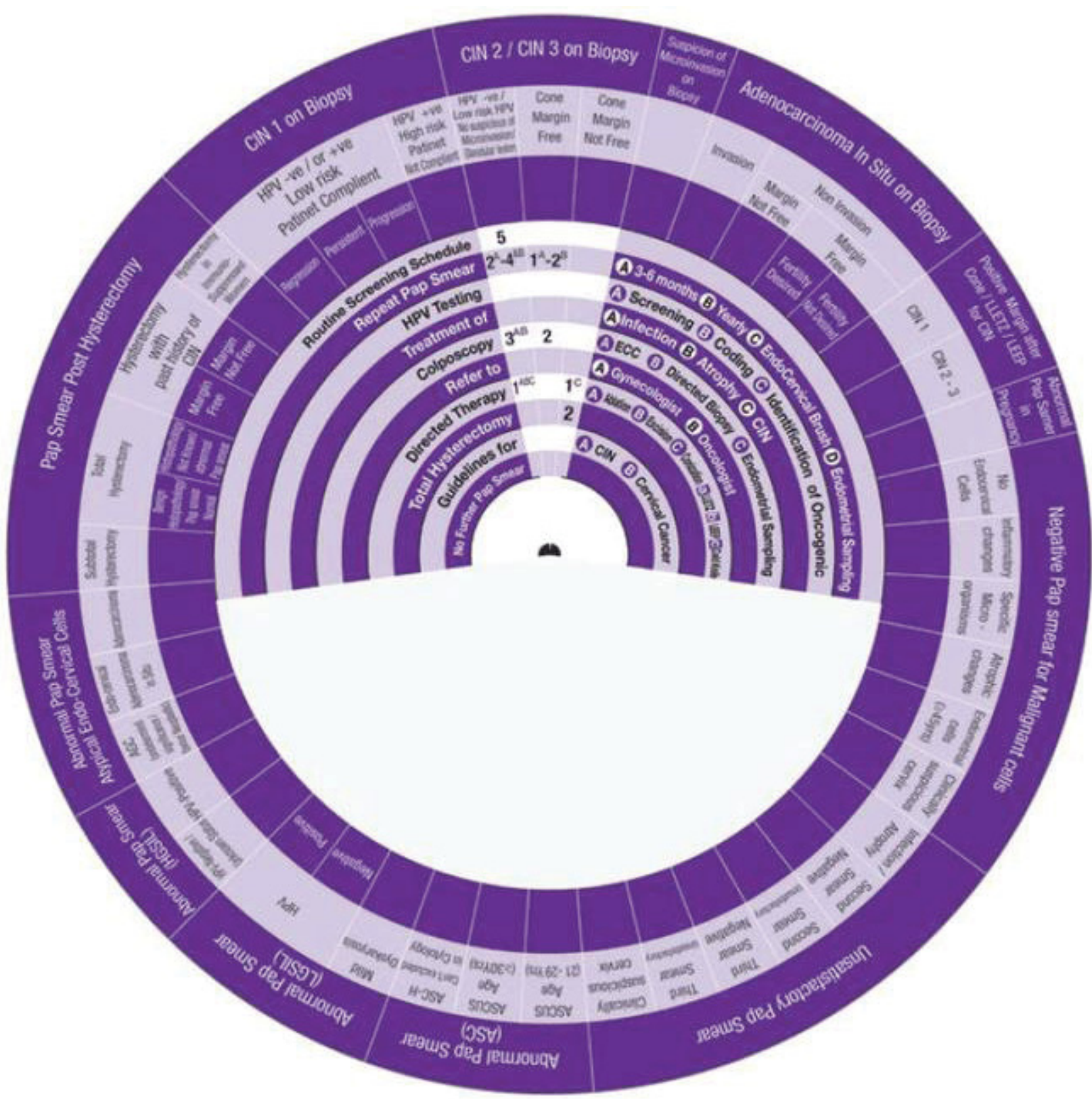

Sector 9: Management of CIN2-3 on Biopsy.

\section{Sector 9: Management of CIN2-3 on Biopsy.}

1. CIN2-3 on Biopsy in women with HPV Negative or Positive with low risk HPV and not suspicious of Micro-invasion or glandular lesion, the Wheel determines the management in Five steps:

Step $1 \rightarrow(1 \mathrm{ABC}) \rightarrow$ Directed Therapy Ablation, Excision, Conization.

Step $2 \rightarrow(2 A) \rightarrow$ Repeat Smear in 3-6 months.

Step $3 \rightarrow(3 \mathrm{AB}) \rightarrow$ Colposcopy ECC + Directed Biopsy.

Step $4 \rightarrow(4 B \&) \rightarrow$ Repeat Smear Yearly+ for five years.

Step $5 \rightarrow(5) \rightarrow$ Routine Screening Schedule.
2. CIN2-3 Cone Margin-free, the Wheel determines the management in Two steps:

Step $1 \rightarrow(1 \mathrm{~A}) \rightarrow$ Repeat Smear in 3-6 months

Step $2 \rightarrow(2-2 B) \rightarrow 2$ Colposcopy $\rightarrow$ 2B Repeat Pap SmearYearly.

3. CIN2-3 Cone Margin-Not free, the Wheel determines management in Two steps:

Step $1 \rightarrow(1 \mathrm{C}) \rightarrow 1 \mathrm{C}$ Directed Therapy Conization.

Step $2 \rightarrow(2) \rightarrow 2$ Total Hysterectomy 


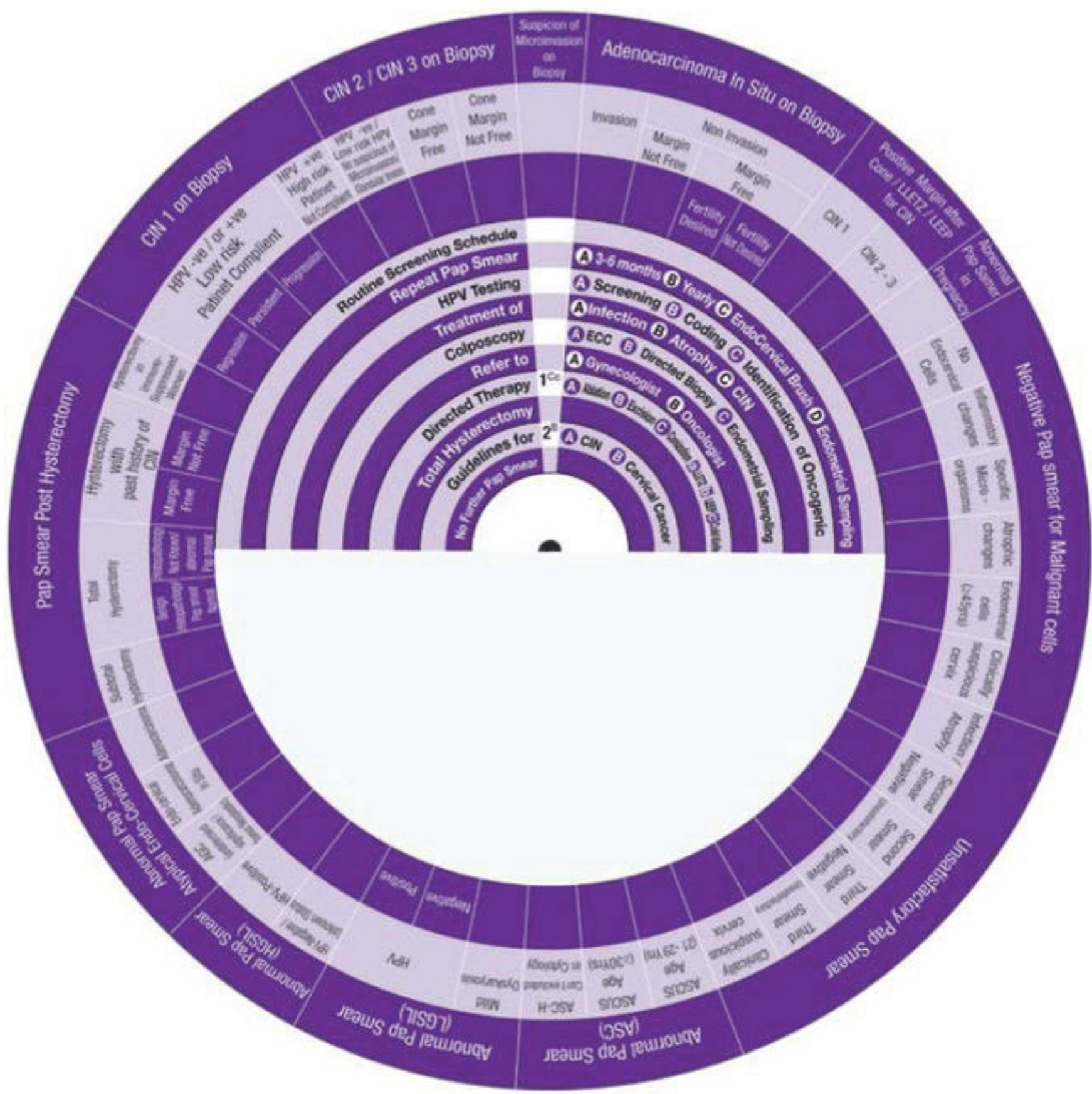

Sector 10: Management of Suspicious of Micro-invasion on Biopsy

Sector 10: Management of Suspicious of Micro-invasion on Biopsy

1. Management of Suspicious of Micro-invasion on Biopsy, the wheel determines the management in One step:

Step $1 \rightarrow(1 \mathrm{Cc}) \rightarrow 1 \mathrm{Cc}$ Directed Therapy Conization-cold knife. 


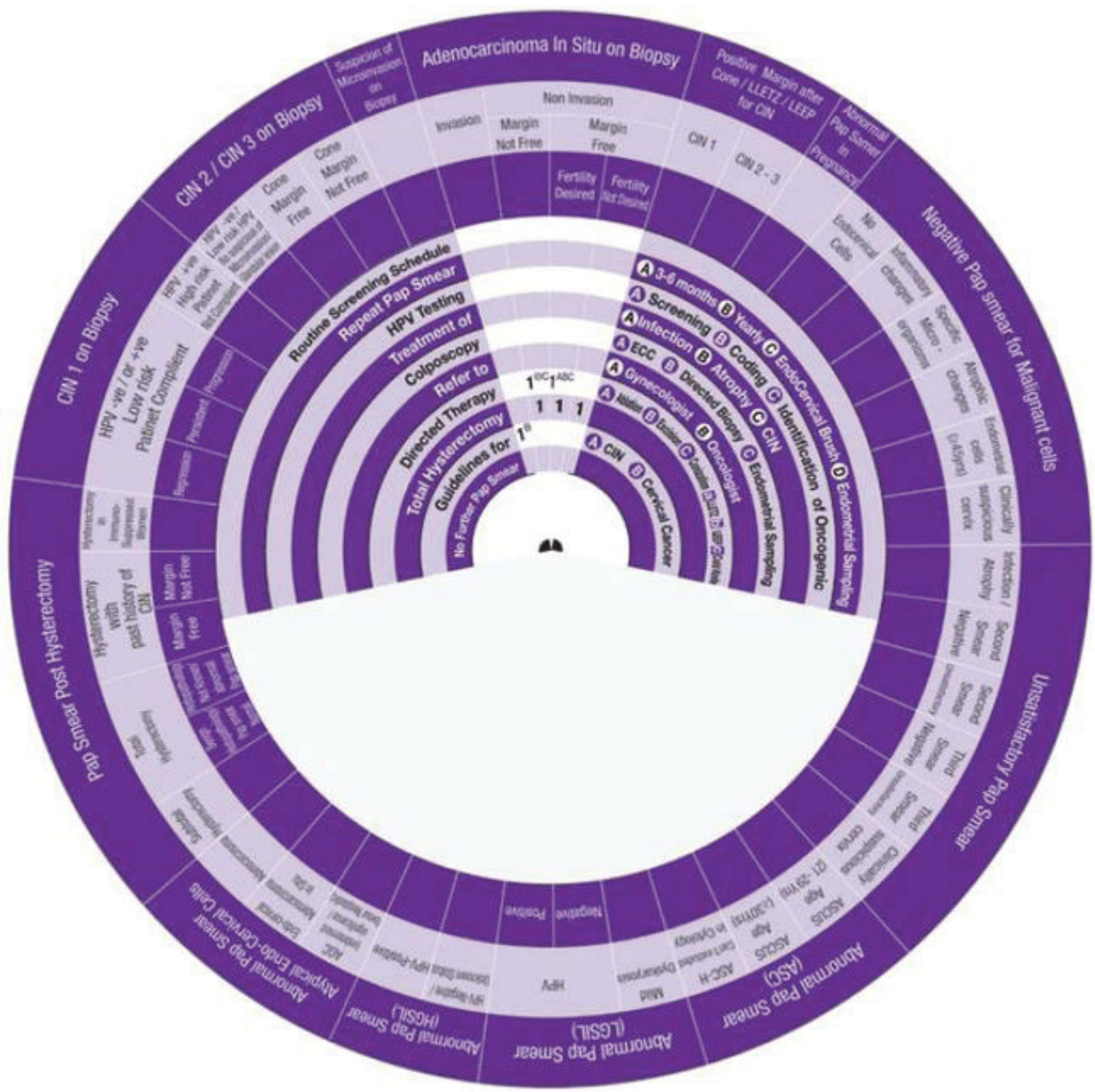

Sector 11: Management of Adeno-carcinoma In Situ (AIS) on Biopsy.

Sector 11: Management of Adeno-carcinoma In Situ (AIS) on Biopsy.

1. Management of invasive Adenocarcinoma on Biopsy, the wheel determines management in One step:

Step $1 \rightarrow 1 \mathrm{~B} \rightarrow$ Guidelines for Cervical Cancer.

2. Management of Non-invasive Adenocarcinoma on Biopsy Margin Not Free, the wheel determines management in One step:

Step $1 \rightarrow 1{ }^{\circledR} \mathrm{C}-1 \rightarrow$ Directed Therapy Re-Conization or Total Hysterectomy.
3. Management of Non-invasive Adenocarcinoma on Biopsy Margin Free Fertility Desired, the wheel determines management in One step:

Step $1 \rightarrow 1 \mathrm{ABC}-1 \rightarrow$ Directed Therapy Ablation, Excision, Conization or Total Hysterectomy.

4. Management of Non-invasive Adenocarcinoma on Biopsy Margin Free Fertility Not Desired, the wheel determines management in One step:

Step $1 \rightarrow 1 \rightarrow$ Total Hysterectomy 


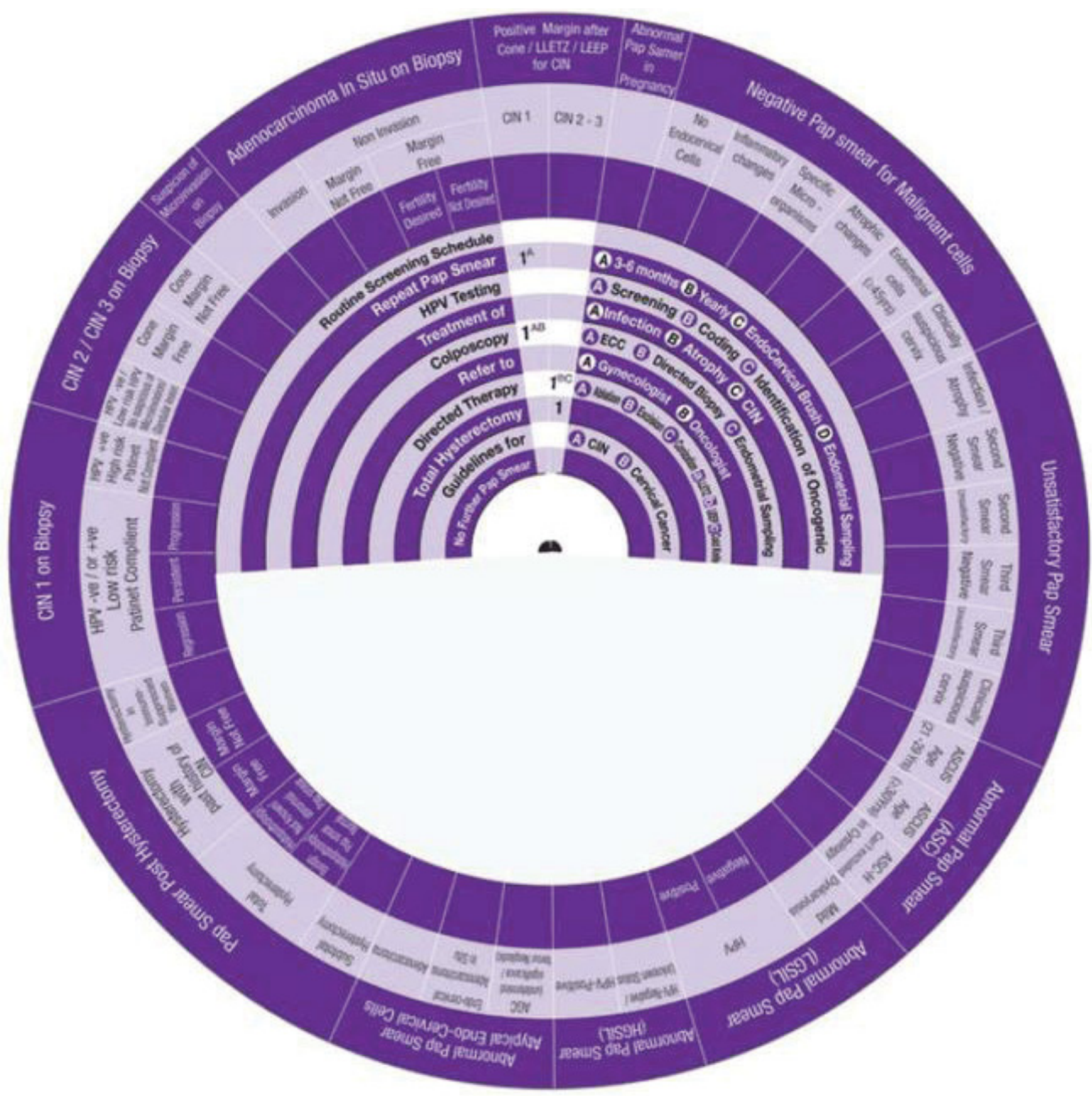

Sector 12: Management of Positive Margin after LEEP/ LLETZ or Conization on Biopsy.

Sector 12: Management of Positive Margin after LEEP/ LLETZ or Conization on Biopsy.

1. Management of Positive Margin/CIN1 after LEEP/ LLETZ or Conization on Biopsy, the Wheel determines management in One step:

Step $1 \rightarrow 1 \mathrm{AB}-1 \mathrm{~A} \rightarrow$ Colposcopy ECC + Directed Biopsy + Repeat Smear in 3-6 months.
2. Management of Positive Margin/CIN2-3 after LEEP/ LLETZ or Conization on Biopsy, the Wheel determines management in One step:

Step $1 \rightarrow 1 \mathrm{ABC}-1 \rightarrow$ Directed Therapy Ablation, Excision, Conization or Total Hysterectomy 


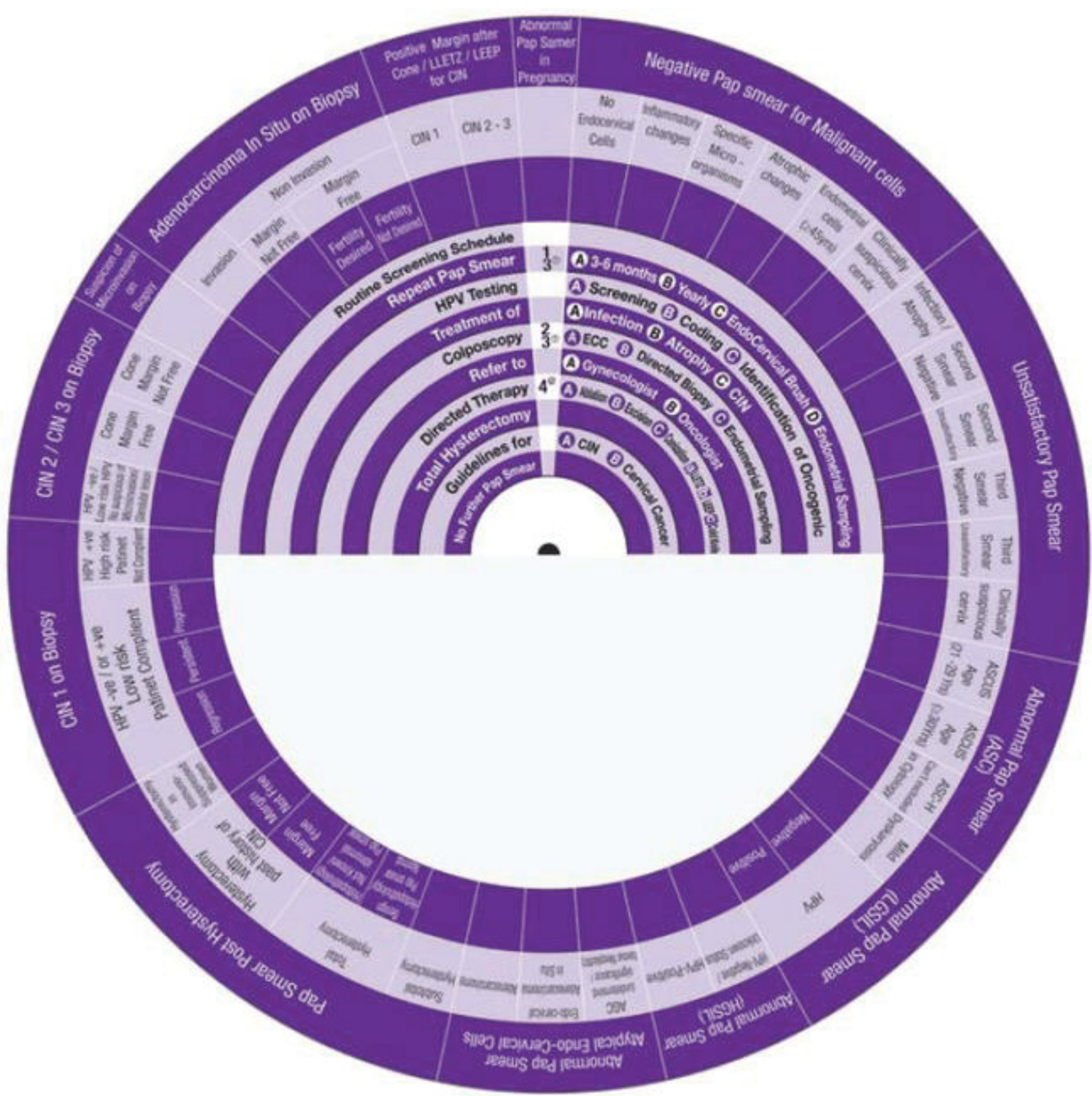

Sector 13: Management of Abnormal Pap Smear in Pregnancy.

Sector 13: Management of Abnormal Pap Smear in Pregnancy.

1. Management of Abnormal Pap Smear in Pregnancy, the wheel determines management in Four steps:

Step $1 \rightarrow(1) \rightarrow 1$ Repeat Pap Smear.

Step $2 \rightarrow(2) \rightarrow 2$ Colposcopy (No contraindication for Colposcopic examination).
Step $3 \rightarrow(3 \mathrm{~T}) \rightarrow 3$ Colposcopy No contraindication for cervical biopsy, Follow up Colposcopic examination should be done in second or third trimester.

Step 4 $\rightarrow$ (4@) $\rightarrow 4$ Directed Therapy, Treatment should be deferred at least until the end of puerperium. No special recommendation for management of labor. 


\section{Discussion}

This Wheel has been designed and developed to facilitate a standard and improve the quality of care in management of abnormal cervical cytology, precancerous lesions and even cancerous lesions of the cervix. It may be the first comprehensive wheel to date. The wheel represents current national-KHUH guidelines, which have been revised from most of the published international guidelines that exist on this subject matter and tailored out from research data compiled by our national healthcare facilities. On the present wheel, the safety of each procedure and step takes into account the context of the patient's medical condition. These determining factors include past medical/surgical history, patient compliance, availability of national/local healthcare facilities and patient awareness regarding the screening process and treatment modalities of precancerous cervical lesions. The safety of the guideline and its effectiveness as a whole should be weighed alongside with the benefits of preventing cervical cancer.

The recommendation within this wheel utilized data from the latest guidelines available from: the World Health Organization (WHO), the American guidelines, guidelines of the American College of Obstetricians and Gynecologists (ACOG), the United States Preventive Services Task Force (USPSTF), the American Cancer Society (ACS), the American Society for Colposcopy and Cervical Pathology (ASCCP), the American Society for Clinical Pathology (ASCP), the American College of Physicians (ACP) and the American Society for Colposcopy and Cervical Pathology, the guidelines from Singapore and Canada, as well as the National Institute for Healthcare and Excellence (NICE) and Nathional Health Service (NHS) of the UK have also been taken into consideration to help providers use these recommendations in practice.

We have compared and evaluated this extensive list of Guidelines in a research paper that has been submitted for publication. As we have described how the recommendations and the wheel were developed, we will now describe how to use the wheel. This Wheel suggests ten action steps in the journey for the managing of abnormal cervical cytology and precancerous lesions:

1. Routine Screening Schedule (according to the program and guideline of the country or the institute).

2. Repeat Pap Smear (either A: in 3-6 months, B: yearly, C: with the use of Endo Cervical Brush or D: in addition to Endometrial Sampling).

3. HPV Testing (either A: Screening, B: Coding, or C: Identification of Oncogenicity).

4. Treatment, (either of A: infection, B: Inflammation, C: Atrophy or D: CIN).

5. Colposcopy (with A: ECC (Endo Cervical Curettage) or B: Directed Biopsy).
6. Refer, to (A: Gynaecologist or B: Oncologist).

7. Directed Therapy, (by A:Ablation, B: Excision, C: Conization (using LEETZ, LEEP or Cold Knife)).

8. Total Hysterectomy.

9. Guidelines, (for A: CIN and B: Cervical Cancer).

10. No Further Pap Smear.

For each abnormal Pap smear section, there are steps placed into one of ten numbered categories. Depending upon cytological or histopathological abnormalities, more than one step may need to be considered together to determine management eligibility. These cytological or histological abnormalities take into account age, HPV status, Pap smear classifications/ grades, CIN, availability of the different treatment modalities, patient compliance, follow up program, availability of a trained colposcopist, pregnancy status and previous treatment interventions like conization or hysterectomy. Our aim through this wheel is to provide guidance to national gynecologists, oncologists, cytologists and pathologists in preparation for the policies and protocols that will be adopted for the delivery of precancerous cervical screening and management services. It is not meant to serve as the actual or obligatory guideline or flow chart rather an idea or a reference which need a further evaluation and feedback. The idea of the wheel successfully applies several international guidelines which we are continuing to work on its feasibility. In particular, the level of clinical knowledge and experience of various types of providers, availability of established programs for screening and management and the resources available at the service delivery point will have to be taken into consideration.

We reviewed some of the recognized guidelines: The American guidelines (American College of Obstetricians and Gynecologists (ACOG), United States Preventive Services Task Force (USPSTF), American Cancer Society/American Society for Colposcopy and Cervical Pathology/American Society for Clinical Pathology (ACS/ ASCCP/ASCP), Centre of Disease Control and Prevention (CDC), American College of Physicians (ACP)), with the following notes:

Positive HPV co-testing results should be immediately followed by HPV genotype-specific testing for HPV 16 or HPV $16 / 18$. This will lead to two routes - colposcopy if the genotypespecific testing is positive or repetition of HPV co-testing in 12 months if the testing is negative [1-5]. Routine age-based screening is only recommended if both atypical squamous cells of undetermined significance (ASCUS) and negative HPV cotesting results occur on screening by cytology; the rationale being that pre-cancerous or invasive lesions are relatively low-yield in HPV-negative women with ASCUS (2). However, if screening by cytology reveals atypical squamous cells that fail to exclude HSIL (ASC-H), low grade squamous intraepithelial lesions (LSIL), high grade squamous intraepithelial lesions (HSIL) or atypical glandular cells (AGC), the recommendation 
is to perform HPV co-testing after 12 months plus referral for colposcopy [1-5]. For women who have a history of CIN 2 or higher and/or have undergone a total or supra-cervical hysterectomy, the ACOG recommends screening by cytology every 3 years for a total of 20 years after the initial posttreatment surveillance period [1-5].

\section{Reviewing screening guidlines for the prevention and early detection of cervical cancer}

The American Society for Colposcopy and Cervical Pathology has established a guideline based on two main age groups; those under 21 years old and those over 21 years old. For ages under 21 , initiation of screening is recommended 3 years after their first sexual intercourse or at the age of 21 , whichever comes first. For ages over 21, screening is advised every 3 years. If the HPV test is positive and cytology is negative, conservatively repeat both tests in 12 months' time regardless of age group. Conversely, if both the HPV test and cytology are positive, colposcopy is recommended. Recommendations have also been specified following cytology results. In patients under 21 years of age who yield ASCUS or LSIL, cytology needs to be repeated in 12 months. If the same findings last beyond a period of 24 months, then the patient should be referred for colposcopy. The same applies to a cytology result that shows AGC at 12 months and then past 24 months.

HSIL on cytology is also an indication for referral to colposcopy. If CIN1 is detected on colposcopy, cytology should be repeated in 12 months, and if the change persists up to 24 months, colposcopy is required again. In patient populations above 21years of age who show ASCUS on cytology, three options are recommended; the HPV test, follow up cytology in 6 or 12 months, and colposcopy. If colposcopy is negative, cytology can be repeated in 6 or 12 months' time or the HPV test in 12 months. If repeated results from either are positive, colposcopy is advised. Any LSIL changes noted on cytology should also be referred for colposcopy. If colposcopy is positive (except for CIN2 and CIN3), cytobrush and endocervical curette is recommended. It is also possible to repeat cytology at 6 or 12 months or repeat the HPV test in 12 months. The initial test recommended for HSIL is a diagnostic procedure, be it immediate loop electrosurgical excision or colposcopy with endocervical assessment. If CIN2/3 is not found on colposcopy and endometrial sampling is negative, diagnostic procedures or cytology or colposcopy can be considered every 6 months. Persistent HSIL at 6 or 12 months warrants excision. If AGC are detected on cytology, colposcopy with endocervical sampling and HPV test are recommended, especially when a high risk of endometrial cancer is suspected. Cases of AIS will require a diagnostic excisional procedure. For instances of CIN1 that last for 2 years or more, adopt a watch and wait approach but if the CIN1 was preceded by HSIL or AGC-NOS, then recommendations include diagnostic excision or cytology and colposcopy in 6 and 12 months. Lastly, as a general rule of thumb, if any unsatisfactory colposcopy, previous treatment, or positive sampling occurs, refer the patient for excision.
Reviewing the NICE guidelines showed: NICE guidelines are largely dependent on HPV co-testing results. If cytology reveals ASCUS or LSIL and positive HPV testing, colposcopy should be done within 8 weeks. If HPV is negative, the patient should continue as per their routine screening schedule. For HSIL positive cytology, the patient should be referred to colposcopy sooner at 4 weeks, irrespective of the HPV test result. Any findings of high-grade dyskaryosis, query invasive squamous cell carcinoma, or query invasive glandular neoplasia of endocervical type or invasive glandular non-cervical neoplasia on cytology should be referred to colposcopy within 2 weeks (1) For CIN lesions: CIN 1 lesions should be followed up with a cytological smear with or without colposcopy at 12 months. The patient can decide whether to start treatment initially or watch and wait to treat only if no regression occurs within 24 months. CIN2 or CIN3 lesions will be treated with ablation or large loop excision of the transformation zone [6].

Guidelines by the Society of Obstetricians And Gynecologists of Canada has focused more on the use of biopsies. They state that borderline changes such as ASCUS or mild dyskaryosis such as LSIL on cytology should first be followed up with colposcopy within 12 weeks. Any discovered lesions on colposcopy should then be biopsied. If there are no lesions found, then a biopsy of the transformation zone should be taken. It is important to note that for women under 21 years old, cytology should always be repeated. If cytology shows atypical squamous cells that cannot exclude HSIL (ASC-H), colposcopy should be performed within 6 weeks. Moderate or severe dyskaryosis (i.e. HSIL) indicates colposcopy within 4 weeks. If no lesions are found on colposcopy, endocervical curettage or directed biopsy is recommended. A diagnostic excisional procedure is necessitated when a lesion is found but the transformation zone is undetectable, and/or the endocervical curettage or biopsy was negative.

Cytological findings of atypical glandular cells or adenocarcinoma in-situ should be followed by colposcopy and endocervical curettage within 6 weeks. Furthermore, if the patient's age exceeds 35 years of age and they present with vaginal bleeding, endometrial sampling will be required. If follow-up colposcopy reveals no lesions, a diagnostic excisional procedure is indicated. The guidelines also highlight options of management for CIN lesions. Patients with CIN1 can be kept under observation with follow up cytology or colposcopy in 12 months. For those with CIN2 or 3 who are older than 25 years of age, excision is recommended. Positive margins can be addressed by colposcopy and directed biopsy and/or endocervical curettage. Lastly, excision is the recommended treatment in case of any recurrent or persistent lesions.

Singapore Guidelines focus on the management of ASCUS, LSIL, HSIL, inflammatory smears, and CIN. If ASCUS is found on cytology, the patient will be recommended a repeat PAP smear in 6 months. If the repeated results are positive, the patient will undergo colposcopy. If negative, it will be repeated again in 6 months until referral back to routine screening (consistently negative smears). If atypical squamous cells are 
found and cannot exclude HSIL (ASC-H), the patient will be referred immediately to colposcopy (3) Mild dyskaryosis such as LSIL indicates colposcopy and if a HPV effect is found or more significant abnormality, cytology should be repeated in 6 months. If the repeated cytology is negative, it will be repeated again in 12 months until referral back to routine screening (consistently negative cytology). For moderate to severe dyskaryosis, AGC, endocervical adenocarcinoma insitu, or invasive carcinoma, referral for colposcopy is indicated [7]. Inflammatory smears follow a treatment timeline. Initially any infection or atrophy should be treated with a repeat smear in 4-6 months. If the follow-up smear has similar changes, treatment should be extended and another smear taken in 4-6 months. If the third smear continues to show the same results, the patient should be referred to a gynecologist. If the inflammation resolves after the first or second smears, the patient should resume their routine screening schedule. For CIN1 lesions, their guidelines state two possible options. The first is use ablation or excision methods initially, perform a PAP smear at 3-6 months, repeat the PAP smear with colposcopy at 12 months, then follow up with annual PAP smears until four negative smears are achieved to return the patient to routine screening. The second option is to first just observe the lesion and repeat a PAP smear with colposcopy +/- biopsy in 6 months (3). CIN2 and CIN 3 lesions should be first treated. Follow up screening will then be done via PAP smear at 3-6 months, a PAP smear with colposcopy at 12 months, then PAP smears every 6 months for the second year until only annual smears are needed [7].

The WHO Guidelines for Screening and Treatment of Precancerous Lesions for Cervical Cancer Prevention focus on initiation of screening for cervical neoplasms at the age of 30 and treatment recommendations according to positive screening results (10). The guidelines highlight HPV testing as a more superior screening tool than cytology, however, algorithms are provided for both methods [8-13].

If the HPV test is negative, repeat screening every 5years. If the test is positive, perform VIA to assess eligibility for treatment with cyotherapy and to exclude cervical cancer. If the VIA is negative, repeat screening in 1-year and then every 3-5 years. If VIA positive, treat the patient with cryotherapy if eligible or with LEEP if not, and then do a follow-up screen in 1year. If cancer is suspected, refer the patient for appropriate diagnosis and treatment.

Colposcopy can also be used as a follow up tool instead of VIA. If colposcopy is negative, repeat screening in 3 years time. If colposcopy is positive and no biopsy was taken, treat with cryotherapy according to eligibility critera or with LEEP if not , then do a follow-up screen in 1 year. If colposcopy was positive and biopsy was done, it depends on the grade of lesion. For $\geq$ CIN2, treat with cryotherapy or LEEP and then do a followup screen in 1 year. If the lesion is $\leq \mathrm{CIN} 1$, repeat screening in 3-years time. Again, if cancer is suspected refer the patient for appropriate diagnosis and treatment $[8-12,14]$.
If screening was done by cytology (PAP smear) and negative, screening should be done every 3-5 years. If cytology is positive ( $\geq$ ASCUS), colposcopy is indicated. The results of the colposcopy determine if a patient should undergo repeat screening in 3 years time (negative results or biopsy showing $\leq$ CIN1), or if they should be treated with cryotherapy or LEEP then followup in a 1 year (positive results without biopsy or biopsy showing $\geq \mathrm{CIN} 2$ ) $[8-12,14]$.

The European Guidelines for Quality Assurance In Cervical Cancer Screening support that the use of HPV testing alone is better than cytology as a screening test for cervical cancer. They have also drawn the conclusion that co-testing catalyzes financial costs and referrals to colposcopy. However, these findings could only be found in patients between the ages of 30-65. Cytology remains the primary screening tool for those beyond this age range [15]. Lengths of follow up are specified in the guidelines according to initial HPV testing and cytology results. If the HPV test is negative, it should be repeated at least every 5 years. For HPV positive tests, cytology will be done on the same sample collected. If the results come back negative, the test will be repeated in 6-12 months. If cytology indicates ASC-H, HSIL or AIS, the patient requires immediate referral to colposcopy. If cytology indicates ASCUS, AGC or LSIL, the patient can either repeat the test in 6-12 months' time or be referred to colposcopy [15].

\section{Acknowledgement}

The guideline for management of abnormal cervical cytology/pathology presented as a Flow Chart and this Wheel were developed by Professor M Samy Ismail, Department of Gynaecology, King Hamad University Hospital (KHUH), Kingdom of Bahrain.

The idea of this wheel was inspired by the WHO Medical Eligibility Criteria for Contraceptive Use, $5^{\text {th }}$ edition (2015) (MEC Wheel). The MEC Wheel is an evidence-based guideline that was developed for providers involved in family planning to recommend safe and effective contraceptive methods for women with medically relevant characteristics or certain medical conditions. Thomas Vaidyan P.K. and Fouad Ismail for helping in the design of the wheel and implementation of the ideas.

Dr. Stephanie Hsu, Research Department, King Hamad University Hospital, Kingdom of Bahrain, for revision of the management guide wheel and manuscript for this research article.

Definitions of the Colposcopic, cytological and pathological terms [13]

- Reporting of Benign-Appearing Endometrial Cells Is Now Recommended for Women Aged $\geq 45$ years

The 2014 bethesda system

Specimen type: Indicates conventional smear (Pap smear) vs. liquid-based preparation vs. other.

\section{Specimen adequacy}

- Satisfactory for evaluation (describe presence or absence of endocervical/transformation zone component and 
any other quality indicators, e.g., partially obscuring blood, inflammation, etc.).

- Unsatisfactory for evaluation. (specify reason).

- Specimen rejected/ not processed (specify reason). Specimen processed and examined, but unsatisfactory for evaluation of epithelial abnormality because of (specify reason).

\section{General Categorization (optional)}

- Negative for Intraepithelial Lesion or Malignancy

- Other: e.g., endometrial cells in a woman 45 years of age.

- Epithelial Cell Abnormality: Specify 'squamous' or 'glandular' as appropriate)

- Negative for intraepithelial lesion or malignancy: When there is no cellular evidence of neoplasia.

- Non-Neoplastic Findings (optional to report).

- Non-neoplastic cellular variations: Squamous metaplasia, Keratotic changes, Tubal metaplasia, Atrophy or Pregnancy-associated changes

- Reactive cellular changes associated with: Inflammation (includes typical repair), Lymphocytic (follicular) cervicitis, Radiation, Intrauterine contraceptive device (IUD).

- Glandular cells status post hysterectomy

- Organisms: Trichomonas vaginalis, Fungal organisms morphologically consistent with Candida spp., Shift in flora suggestive of bacterial vaginosis, Bacteria morphologically consistent with Actinomyces spp. Cellular changes consistent with herpes simplex virus, Cellular changes consistent with cytomegalovirus or other like Endometrial cells (in a woman $\geq 45$ years of age.

\section{Epithelial cell abnormalities}

- Atypical squamous cells of undetermined significance (ASC-US)

\section{- Cannot exclude HSIL (ASC-H)}

- Low-grade squamous intraepithelial lesion (LSIL) (encompassing: HPV/mild dysplasia/CIN 1)

- High-grade squamous intraepithelial lesion (HSIL) (encompassing: moderate and severe dysplasia,

- CIS; CIN 2 and CIN 3 with features suspicious for invasion (if invasion is suspected) $3 / 4$ Squamous cell carcinoma

\section{Glandular cell}

- Atypical: endocervical cells (NOS or specify in comments)

- Endometrial cells (NOS or specify in comments)

- Glandular cells (NOS or specify in comments)

\section{- Atypical:}

- Endocervical cells, favor neoplastic

- Glandular cells, favor neoplastic $3 / 4$ Endocervical adenocarcinoma in situ 3/4 Adenocarcinoma

Endocervical

- Endometrial

- Extrauterine

- Not otherwise specified (NOS) OTHER MALIGNANT NEOPLASMS: (specify) ADJUNCTIVE TESTING Provide a brief description of the test method(s) and report the result so that it is easily understood by the clinician. COMPUTER-ASSISTED INTERPRETATION OF CERVICAL CYTOLOGY If case examined by an automated device, specify device and result.

- Educational Notes and Comments Appended to Cytology Reports (optional) Suggestions should be concise and consistent with clinical follow-up guidelines published by professional organizations (references to relevant publications may be included).

\section{References}

1. Canadian Task Force on Preventive Health Care (2013) Recommendations on screening for cervical cancer. CMAJ 185: 35-45. Link: https://bit.ly/33blezX

2. Saslow D, Solomon D, Lawson HW, Killackey M, Kulasingam SL, et al. (2012) American Cancer Society, American Society for Colposcopy and Cervical Pathology, and American Society for Clinical Pathology Screening Guidelines for the Prevention and Early Detection of Cervical Cancer. CA Cancer J Clin 62 147-172. Link: https://bit.ly/2vjW8DS

3. Palefsky JM (2017) Human papillomavirus infections: Epidemiology and disease associations. Link: https://bit.ly/33dMUoV

4. Arbyn M, Anttila A, Jordan J, Ronco G, Schenck U, et al. (2010) European Guidelines for Quality Assurance in Cervical Cancer Screening. Second Edition-Summary Document. Ann Oncol 21: 448-458. Link: https://bit.ly/38JF5sq

5. Frumovitz M (2017) Invasive cervical cancer: Epidemiology, risk factors, clinical manifestations, and diagnosis. Link: https://bit.ly/2wLUefw

6. Bruni L, Albero G, Serrano B, Mena M, Gómez D, et al. (2017) Human Papillomavirus and Related Diseases Report in Bahrain. HPV Information Centre. Link: https://bit.ly/2IBTDQj

7. Clinical Knowledge Summaries N (2015) Cervical Screening

8. Peirson L, Fitzpatrick-Lewis D, Ciliska D, Warren R (2013) Screening for cervical cancer: a systematic review and meta-analysis. Syst Rev 2: 35. Link: https://bit.ly/2veJ6r3 
9. Prevention CODCA (2015) Cervical Cancer Screening Guidelines for AverageRisk Women. Link: https://bit.ly/3cT5ck0

10. Prevention CODCA (2015) Rationale for Screening Recommendations.

11. Feldman S, Goodman A, Peipert JF (2019) Screening for cervical cancer. Link: https://bit.ly/39JeTQ7

12. WHO (2013) WHO guidelines for screening and treatment of precancerous lesions for cervical cancer prevention. Link: https://bit.ly/2W6Ypgs
13. WHO (2017) Human papillomavirus (HPV) WHO. Link: https://bit.ly/2vZ3OM2

14. Kujur $P$, Joshi $C$ (2015) Application of the 2014 Bethesda system for reporting of cervical/vaginal cytological lesions. J Evolut Med Sci 4: 16366+. Link: https://bit.ly/39JKJMx

15. Hong HT (2019) Management guidelines for abnormal pap smear and preinvasive disease of the cervix. Preface. Link: https://bit.ly/38GcDaH

Discover a bigger Impact and Visibility of your article publication with

Peertechz Publications

\section{Highlights}

* Signatory publisher of ORCID

* Signatory Publisher of DORA (San Francisco Declaration on Research Assessment)

* Articles archived in worlds' renowned service providers such as Portico, CNKI, AGRIS, TDNet, Base (Bielefeld University Library), CrossRef, Scilit, J-Gate etc.

* Journals indexed in ICMJE, SHERPA/ROMEO, Google Scholar etc.

* OAI-PMH (Open Archives Initiative Protocol for Metadata Harvesting)

* Dedicated Editorial Board for every journa

* Accurate and rapid peer-review process

* Increased citations of published articles through promotions

* Reduced timeline for article publication

Submit your articles and experience a new surge in publication services (https://www.peertechz.com/submission).

Peertechz journals wishes everlasting success in your every endeavours.

Copyright: (c) 2020 Ismail MS. This is an open-access article distributed under the terms of the Creative Commons Attribution License, which permits unrestricted use distribution, and reproduction in any medium, provided the original author and source are credited.

Citation: Ismail MS (2020) Development of A Management Guideline Wheel for Abnormal Pap Smears and Related Cervical Pathology. Ann Cytol Pathol 5(1): 013034. DOI: https://dx.doi.org/10.17352/acp.000012 